\title{
Evaluation of Enzyme-Linked Immunosorbent Assay (ELISA) and Immunofluorescent Antibody (IFA) Test for the Detection of Porcine Reproductive and Respiratory Syndrome Virus (PRRSV) Antibody in Pigs from Conventional Farms
}

\author{
Yoshihiro YAHARA $^{1)}$, Yukihiro OHKUBO $^{1)}$, Hiroaki KARIWA ${ }^{2)}$ and Ikuo TAKASHIMA ${ }^{2)}$ \\ ${ }^{1)}$ Veterinary Service Center, Nisshin Feed Inc., 5-3-1 Tsurugaoka, Oi-machi, Iruma-gun, Saitama 356-8511 and ${ }^{2)}$ Laboratory of Public \\ Health, Department of Environmental Veterinary Sciences, Graduate School of Veterinary Medicine, Hokkaido University, Sapporo 060- \\ 0818, Japan
}

(Received 11 September 2001/Accepted 19 March 2002)

ABSTRACT. To evaluate the immunofluorescent antibody (IFA) test and enzyme-linked immunosorbent assay (ELISA) for detecting the porcine reproductive and respiratory syndrome virus (PRRSV) antibody, conventional pigs in PRRSV-positive and -negative commerci al farms were examined. Antibody development patterns in ELISA and IFA tests were compared in 3 week old piglets experimentally infected with the PRRSV. The virus was detected from 2 days post infection (PI) and then the antibody titers and S/P ratios rose by both methods. A total of 208 serum samples were collected from 4 PRRSV-negative farms and 210 samples from PRRSV-positive farms, and were tested for the PRRSV antibody by IFA and ELISA. The titer of 64 should be set as the cut-off point in IFA for field sera. Similarly, the cut-off S/P ratio should be set at 0.4 in ELISA. A high degree of correlation was observed between antibody titers by the two methods in these 418 samples, with a correlation coefficient of 0.84 . The coincidence rate between the two tests was $84.7 \%$ (354/418). In non-coincident cases, ELISA was able to detect the antibody with a low titer in the serum samples which were negative in IFA but from PRRSV positive farms. ELISA was more sensitive than IFA to detect PRRSV infected animals or farms. KEY WORDS: antibody, conventional farm, ELISA, IFA, PRRS.

J. Vet. Med. Sci. 64(7): 583-588, 2002

Since porcine reproductive and respiratory syndrome (PRRS) was first reported in 1991 [24], the high prevalence rate of PRRS has been demonstrated worldwide [3, 5, 9, 17]. This has caused serious economic loss to pig farming industries due to the decreased growth rate of weaning piglets and the reproduction abnormalities $[18,19]$. In Japan, PRRS has been reported since $1993[15,20]$ and the reported data show a high prevalence rate [2]. In many commercial farms in the world, some endemic respiratory diseases cause a mixed infection called porcine respiratory disease complex (PRDC), and PRRS is one of the most basic parts of PRDC $[4,21]$. When monitoring such an endemic disease in order to build health program, it is very important to know the stage at which infection starts and at which PRRS becomes severe. Therefore a highly sensitive and specific assay is needed. The IFA, the immunoperoxidase monolyer assay (IPMA), the virus neutralization test (VNT), and the haemaglutination inhibition test (HI) have been reported as antibody assays of PRRS virus (PRRSV) [1, 7, 8, 13, 23, 27, 29]. IFA has been most frequently used for PRRS in Japan. Recently, however, the ELISA has been developed and has increasingly displaced the IFA for diagnostic assay because of its simple protocol and high sensitivity $[6,11,22,30]$. The judgement of the ELISA results was analyzed in gnotobiotic pigs experimentally infected with the PRRSV and a cut-off point was set at an S/P ratio of 0.4 [30]. However, conventional pigs reared at commercial farms often show a non-specific reaction in serological tests due to the antigenic stimuli of various microorganisms. Therefore, prior to application of ELISA for field survey, sera from field pigs should be examined to determine the cut-off point in comparison with IFA results.

In this study, we evaluated IFA and ELISA for detecting the PRRSV antibody in experimentally infected pigs and conventional pigs from commercial farms. PRRSV antibody titers were tested by both tests in pig sera from positive and negative farms. Distribution patterns of antibody titers were compared between the two groups of samples from negative and positive farms. From those results, cut-off values for IFA and ELISA in the field situation were determined and applicabilities of the two tests were discussed.

\section{MATERIALS AND METHODS}

Experimental infection: PRRSV strains S-1 and S-30 were used for the experimental infection of pigs. These strains were isolated from the sera of field pigs at the acute stage of PRRSV infection in July 1993, using swine alveolar macrophage (SAM) cells [25]. Four healthy piglets reared at a conventional farm were transferred to an isolation facility and used for experimental infection at 21 to 25 days old. Each piglet received $5 \mathrm{ml}$ of $10^{4.5} \mathrm{TCID}_{50} / \mathrm{m} l$ of the $S-1$ strain or S-30 strain intranasally. One pig (No.1) received the S-30 strain and two pigs (Nos. 2 and 3) the S-1 strain. One pig (No. 4) served as a non-infection control. After virus inoculation, each animal was reared separately and observed every day for clinical signs such as vigor, appetite and abnormal respiration. Blood was collected from ani- 
mals at 2, 5, 8, 14 and 22 days post infection (PI). Sera were subjected for virus isolation and antibody testing by IFA and ELISA. Virus isolation proceeded using SAM as described by Yoon et al. [26].

Field serum samples: Serum samples of 418 individuals were collected from 12 pig farms from December 1994 to July 1998. These sera were classified into 2 groups; one group (208 sera) from 4 negative farms and the other (210 sera) from 8 positive farms. At the negative farms, none of the animals showed the antibodies either by IFA (titer $\geq 64$ ) or by ELISA ( $\mathrm{S} / \mathrm{P}$ ratio $\geq 0.4$ ) during the 3 years survey. And at these negative farms, any clinical PRRS symptoms were never seen during this period. At the positive farms, some animals had the antibodies by IFA (titer $\geq 64$ ). This tentative cut-off point of IFA (titer of 64) was referred to Yoon et al. [27]. They speculated that IFA cut-off titer might be set at 64, when conventional pigs were tested. And ELISA tentative cut-off value was set at 0.4 , which was recommended in the manufacture's instructions, and was examined using sera from pigs in high health status.

Immunofluorescent antibody test (IFA): SAM cells used in IFA were collected from three to six weeks old Landrace pigs in PRRSV free SPF farms, and were not detected any viruses showing CPE in SAM cells nor any bacteria contamination. These SAM cells were seeded in a 6-well plastic microplate (Iwaki Glass, Japan) with $2.0 \times 10^{6}$ cells/well and each well was inoculated with the PRRSV S-1 strain at $10^{4} \mathrm{TCID}_{50} /$ well. After incubation at $37^{\circ} \mathrm{C}$ for $1 \mathrm{hr}$, each well received $5 \mathrm{~m} l$ of RPMI1641 medium containing $5 \%$ fetal calf serum (FCS) and the plate was incubated in a $5 \%$ $\mathrm{CO}_{2}$ incubator. After 48 to $60 \mathrm{hr}$ of incubation, SAM cells showing $30 \%$ CPE were collected by centrifugation and resuspended at $3.0 \times 10^{5}$ cells $/ \mathrm{m} l$ in phosphate buffered saline (PBS). The cell suspension was added to each well $(0.01 \mathrm{ml} /$ well $)$ of 24 well slide glasses. After air-drying, the antigen slide was fixed in methanol for $20 \mathrm{~min}$ and stored at $-20^{\circ} \mathrm{C}$. SAM cells without virus infection were similarly treated and used as an antigen negative control.

IFA was performed according to the procedure described by Yoon et al. [27]. Briefly, the test sera were heat-inactivated at $56^{\circ} \mathrm{C}$ for $30 \mathrm{~min}$, and were then diluted serially 4fold from $1: 16$ to $1: 1,024$ in PBS. Only the serum of the 1:16 dilution series reacted with antigen negative slides. The reciprocal of highest serum dilution showing specific intracytoplasmic fluorescence was defined as the antibody titer of the serum. A serum sample showing positive fluorescence at 1:16 dilution against negative antigen was excluded as judgment impossible from the analysis due to the non-specific reaction.

ELISA procedure: ELISA for PRRSV was carried out, using a commercially available kit (IDEXX, U.S.A.). The assay procedure was followed by the manufacture's instructions. Each sample was judged according to the S/P.

$\mathrm{S} / \mathrm{P}$ ratio calculation formula :

$\mathrm{S} / \mathrm{P}=[($ absorbance value of sample in PRRS well $)-$ (absorbance value of sample in NHC well)]/[(mean absorbance value of PC in PRRS well) - (mean absorbance value of $\mathrm{PC}$ in $\mathrm{NHC}$ well)]

$\mathrm{PC}:$ positive serum control

NHC : normal host cell

Evaluation of non-coincident cases: Out of the sera showed non-coincident results in IFA and ELISA, available samples were tested by VNT and examined for PRRSV gene by the reverse transcription-polymerase chain reaction (RT-PCR) to evaluate which result is reliable. VNT was carried out according to the procedure of Takikawa et al. [23]. RT-PCR was also performed by the method of Kono et al. [14].

\section{RESULTS}

Experimental infection: For comparison of antibody development patterns in ELISA and IFA, the sera were obtained consecutively from experimentally infected pigs and utilized for virus detections and antibody assays. The infected pigs showed only a mild abdominal type of respiration disorder and a decrease of feed intake, although field strains from pigs with severe respiratory symptoms were used for the experimental infection. The viruses were detected from the sera of the animals at 2 days PI and thereafter, indicating the establishment of infection (Table 1).

IFA and ELISA antibodies were examined in the consecutive sera from infected pigs (Table 2). The IFA antibody titers were $\leq 16$ in non-infected control pigs, but the titers rose $\geq 64$ in infected animals at 8 to 14 days PI. ELISA antibody $\mathrm{S} / \mathrm{P}$ ratios were 0.101 or lower in non-infected animals during the observation period. The $\mathrm{S} / \mathrm{P}$ ratios of infected animals were $>0.2$ in all the sera at 8 days PI and increased to 0.834 and 2.402 at 14 and 22 days PI, respectively.

Distribution of IFA titer and ELISA S/P ratio in the sera

Table 1. Virus detection in weaning pigs following experimental infection with PRRS virus

\begin{tabular}{cccccccc}
\hline & & \multicolumn{7}{c}{ Virus detection from sera } \\
\cline { 3 - 7 } Pig No. & Infected strain & 0 & 2 & 5 & 8 & 14 & 22 \\
\cline { 3 - 7 } & S30 & - & + & + & + & + & ND \\
2 & S1 & - & + & + & + & + & + \\
3 & S1 & - & + & + & + & + & ND \\
4 & Control & - & - & - & - & - & ND \\
\hline
\end{tabular}

ND: Not done. 
Table 2. Antibody response in weaning pigs following experimental infection with PRRS virus

\begin{tabular}{cccccccc}
\hline & & \multicolumn{6}{c}{ Antibody response (IFA titer/ELISA S/P ratio) } \\
\cline { 3 - 7 } & & & \multicolumn{5}{c}{ Days post infection } \\
\cline { 3 - 7 } Pig No. & Infected strain & 0 & 5 & 8 & 14 & 22 \\
\hline 1 & S30 & $<16 /-0.064$ & $<16 /-0.047$ & $<16 / 0.051$ & $64 / 0.466$ & $64 / 0.834$ & ND \\
2 & S1 & $<16 /-0.014$ & $<16 /-0.019$ & $16 /-0.012$ & $16 / 0.271$ & $64 / 1.566$ & $256 / 2.402$ \\
3 & S1 & $<16 /-0.031$ & $<16 /-0.047$ & $<16 /-0.039$ & $16 / 0.248$ & $64 / 1.583$ & ND \\
4 & Control & $<16 / 0.101$ & $<16 / 0.062$ & $<16 / 0.002$ & $<16 /-0.019$ & $16 /-0.019$ & ND \\
\hline
\end{tabular}

ND: Not done.

of field animals: The sera from two groups of pigs, one from negative farms and the other from positive farms were tested for the PRRSV antibody by IFA and ELISA. In the negative farms, none of pigs tested during a 3 year period showed antibodies either by IFA (titer $\geq 64$ ) or by ELISA (S/P ratio $\geq 0.4$ ). The distribution of the IFA antibody titers in the sera from positive and negative farms are shown separately (Fig. 1). The titers of the negative farm animals showed one peak at a titer of $<16$, while the titers of the positive farm animals formed one peak at a titer of 64 . When the titer of 16 was set as a cut-off titer, the 64 samples from the negative farms were judged as false positive. Therefore, a titer of 64 should be set as a cut-off point in IFA for field sera.

The same sera collected from the negative and positive farms were also examined by ELISA. The S/P ratios were shown separately for negative and positive farms (Fig. 2). Almost all negative farm samples $(159 / 161,98.8 \%)$ showed a $\mathrm{S} / \mathrm{P}$ ratio $<0.4$. Positive farm samples formed a peak at the ratio of 0.8 to $<1.2$ with the highest ratio at 3.690. From these results, the cut-off point of ELISA for field samples may be set at a ratio of 0.4 , which was at the bottom between the two peaks. The cut-off ratio corresponded with the value indicated in the kit which was determined in experimental infection using gnotobiotic pigs.

Correlation of IFA and ELISA results: The correlation between the IFA titer and the ELISA S/P ratio of the field sera was examined (Fig. 3). Antibody values of the two tests distributed with nearly linear regression. The correlation coefficient between the two tests was 0.84 . From the above results, cut-off values were determined finally at a titer of 64 for IFA and an S/P ratio of 0.4 for ELISA. The coincidence rate between both tests was $84.7 \%$ (354 of 418) (Table 3). Non-coincident results were found in 64 samples, of which 63 were IFA negative and ELISA positive (Table $3)$. Out of the 63 samples, $61(96.8 \%)$ samples were from positive farms and $2(3.2 \%)$ samples from negative farms (Table 4).

Evaluation of non-coincident cases: Out of the 64 sera showed non-coincident results in IFA and ELISA, available 12 samples were tested by VNT and examined for PRRSV gene by RT-PCR (Table 5). Of the 12 samples, 10 samples were IFA negative and ELISA positive from one positive farm (group 1). One sample was IFA negative and ELISA positive from one negative farm (group 2). And last one sample was IFA positive and ELISA negative from one pos-

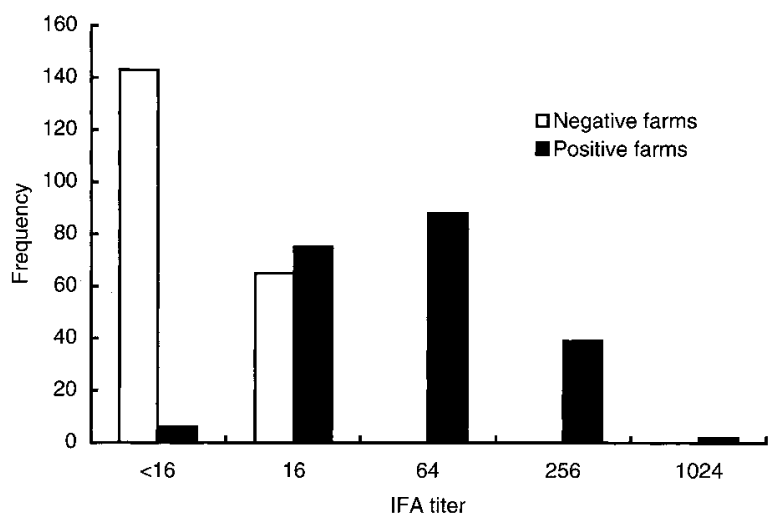

Fig. 1. Frequency distribution of PRRSV IFA titers.

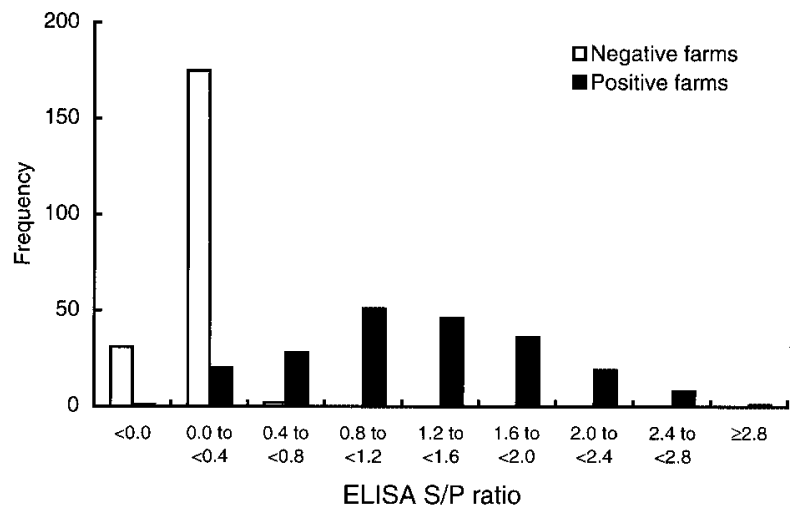

Fig. 2. Frequency distribution of PRRSV ELISA S/P ratios.

itive farm (group 3).

All of the 10 samples of group 1 was VNT positive or RTPCR positive. But two samples of group 2 and 3 were negative by the both methods. These results supported the ELISA data in the 10 samples of group 1 and one sample of group 3. In the sample of group 2, a negative result of IFA was supported.

\section{DISCUSSION}

In this study, we compared IFA and ELISA as serological 


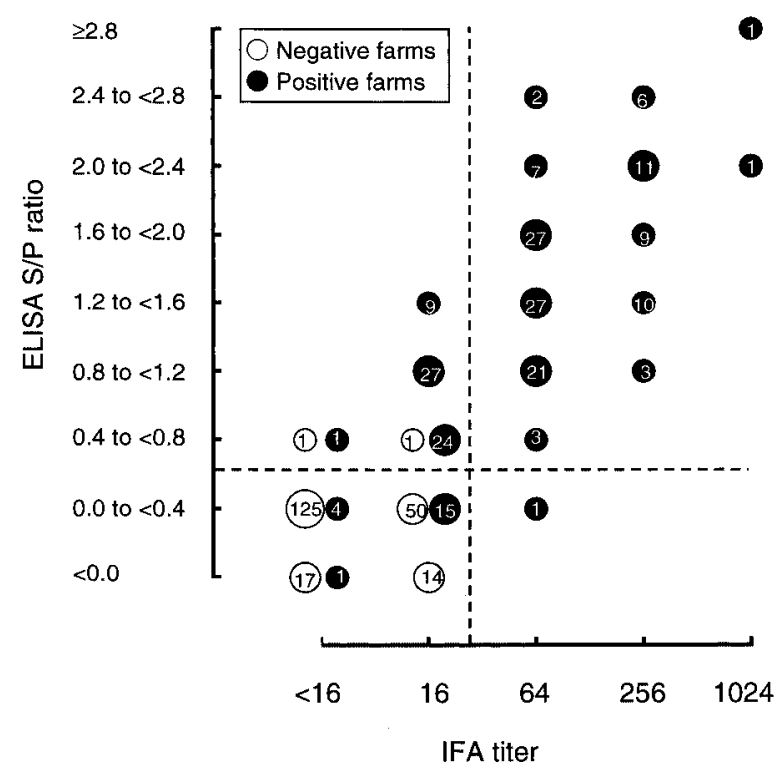

Fig. 3. Correlation of PRRSV IFA titers and ELISA S/P ratios. Numbers in circle symbols show frequency of the cases and the correlation coefficiency $(r)$ is 0.84 .

diagnostic tests for PRRSV infection of pigs both in experimental infection and field situation. In the experimental infection, viremia was detected at 2 days PI and thereafter, showing the establishment of the infection. The result corresponded with the previous reports [28]. Antibody development patterns were almost the same in IFA and ELISA. In the non-infected control pig, IFA titer was 16 at 14 days PI. But this titer seemed non-specific reaction, because it was not observed any clinical symptoms, and not detected PRRSV from the sera of this pig.

A cut-off value for the positive PRRSV ELISA antibody could be set at S/P ratio of 0.4 in the field situation due to the following, 1) ELISA antibodies distributed in two peaks with a S/P ratio of 0.4 to $<0.8$ at the bottom, 2) most of the negative farm animals $(98.8 \%, 159 / 161)$ showed a $\mathrm{S} / \mathrm{P}$ ratio $<0.4$. The ELISA criteria made it possible to reduce both the false positive and negative samples to a minimum number. In contrast, the IFA antibody titer distributed in the overlapping patterns of positive and negative farms. The cut-off point of IFA was set at an antibody titer of 64 , which generated a large number of false negative samples. If the cut-off point were to be set at 16 , the false positive samples would increase.

Results in IFA and ELISA were not coincident in 64 samples of which 63 were ELISA positive and IFA negative. Of the 63 samples, 61 were from PRRSV positive farms. Available 10 samples from the 61 sera were tested by VNT and RT-PCR, and all 10 samples was positive either by VNT or RT-PCR. These results suggested that the most of samples of ELISA positive and IFA negative were false negative in IFA. And the sample of ELISA negative and IFA positive was negative by VNT and RT-PCR. This case seemed to be false positive in IFA. In the negative farm, the case seemed false positive in ELISA was observed, but this was a very rare case. Takikawa et al. [22] reported it was observed many non-coincident cases of ELISA positive and IFA negative, and speculated these cases were false negative in IFA. In this study, it could be clear that many of such non-coincident cases were observed in PRRSV positive farms, and high rate of these cases were PRRSV positive as the judgement of ELISA.

From the results listed above, ELISA seems to be more sensitive than IFA for detecting the PRRSV antibody in a field situation. One reason for this might be due to the fact that the cut-off titer for IFA was set at 64, resulting in the increase of false negative samples. The other reason might be due to the difference of antigen preparation procedures in both tests. The antigen for IFA was prepared by fixing PRRSV infected SAM cells. The amount of viral antigen in fixed SAM cells was restricted up to the highest limit of $10^{4.5} \mathrm{TCID}_{50} / \mathrm{m} l$. However, ELISA incorporates antigen of liquid state in which the concentration of antigen can be increased to the optimum.

A difference in the virus strains used in both tests might have influenced to the sensitivities of the tests. The PRRSV strains were classified into two types, U.S.type and Lelystad (E.U.) type $[12,16]$. Two virus strains of U.S. and Lelystad types were used as the mixture of antigen for ELISA, but only S-1 strain of U.S. type was used in IFA. False negative samples in IFA might have on antibody to the Lelystad type strain.

In the screening conventional farms for PRRSV by serological test in an endemic region such as Japan, the false negative samples should be at the least level in order to find exact onset time of infection, and segregate PRRSV-negative piglets from the infected group. For this purpose, ELISA was suggested to be a better serological test than IFA. The correlation of IFA and ELISA (Fig. 3, Tables 3,4 and 5) showed that ELISA was able to detect a PRRSV anti-

Table 3. Correlation of IFA and ELISA results

\begin{tabular}{lcccc}
\hline & \multicolumn{3}{c}{ IFA frequency $(\%)$} \\
\cline { 2 - 5 } & & $+(\geq 64)$ & $-(<64)$ & Total \\
\hline \multirow{3}{*}{ ELISA frequency $(\%)$} & $+(\geq 0.4)$ & $128(30.6)^{\mathrm{a})}$ & $63(15.1)$ & $191(45.7)$ \\
& $-(<0.4)$ & $1(0.2)$ & $226(54.1)^{\mathrm{a})}$ & $227(54.3)$ \\
\cline { 2 - 5 } & Total & $129(30.9)$ & $289(69.1)$ & $418(100.0)$ \\
\hline
\end{tabular}

a) Ratio of cases coincident in both tests is $84.7 \%$. 
Table 4. Frequency of non-coincident results on positive and negative farms

\begin{tabular}{lccc}
\hline & \multicolumn{3}{c}{ Frequency (\%) } \\
\cline { 2 - 4 } Case & Positive farms & Negative farms & All farms \\
\hline IFA (-) and ELISA (+) & $61(96.8)$ & $2(3.2)$ & 63 \\
IFA (+) and ELISA (-) & $1(100.0)$ & $0(0.0)$ & 1 \\
\hline
\end{tabular}

body of low titer not detectable by IFA.

It was recommended to segregate non-infected weaning group from the elder infected group to prevent the spread of PRRSV. Nursery depopulation and multiple site production system were designed for this purpose [10]. However, the varying onset time of infection makes a PRRSV control programs of the segregated production system very difficult. Due to its good sensitivity, ELISA may be useful in a control program by determining the time for the onset time of infection and enables to differentiate PRRSV-negative and infected piglets efficiently.

ACKNOWLEDGMENT. We are grateful to Dr. Han-Soo Joo, Department of Clinical and Population Sciences, University of Minnesota, for many advices on isolation and diagnosis of PRRSV.

\section{REFERENCES}

1. Alstine, W. G. V., Stevenson, G. W. and Kanitz, C. L. 1993. Diagnosis of porcine reproductive and respiratory syndrome. Swine Health Prod. 1: 24-28.

2. Asai, T., Mori, M., Niinuma, S., Osumi, T., Otagiri, Y., Hayashi, Y., Kitajima, K. and Hirai, H. 2000. A survey of antibodies to the porcine reproductive and respiratory syndrome virus in Japan. J. Jpn. Vet. Med. Assoc. 53: 363-366.

3. Bautista, E. M., Morrison, R. B., Goyal, S. M., Collins, J. E. and Annelli, J. F. 1993. Seroprevalence of PRRS virus in the United States. Swine Health Prod. 1: 4-8.

4. Carlton, J. 1998. Mycoplasma's critical interaction with the PRRS virus in PRDC (porcine respiratory disease complex). Swine Pract.: 20-22.

5. Cheon, D. S., Chae, C. H. and Lee, Y. S. 1997. Seroprevalence of antibody to porcine reproductive and respiratory syndrome virus using enzyme-linked immunosorbent assay in selected herds in Korea. J. Vet. Diagn. Invest. 9: 434-436.

6. Cho, H. J., Deregt, D. and Joo, H. S. 1996. An ELISA for porcine reproductive and respiratory syndrome: production of antigen of high quality. Can. J. Vet. Res. 60: 89-93.

7. Cho, H. J., McNab, B., Dubuc, C., Jordan, L., Afshar, A., Magar, R., Prins, S. and Eernisse, K. 1997. Comparative study of serological methods for the detection of antibodies to porcine reproductive and respiratory syndrome virus. Can. J. Vet. Res. 61: 161-166.

8. Cho, S. H., Freese, W. R., Yoon, I. J., Trigo, A. V. and Joo, H. S. 1993. Seroprevalence of indirect fluorescent antibody to porcine reproductive and respiratory syndrome virus in selected swine herds. J. Vet. Diagn. Invest. 5: 259-260.

9. Christianson, W. T. and Joo, H. S. 1994. Porcine reproductive and respiratory syndrome: a review. Swine Health Prod. 2: 1028.
Table 5. VNT titers and RT-PCR results of non-coincident samples on positive and negative farms

\begin{tabular}{lcccc}
\hline Case & Farm & Group & VNT titer & RT-PCR \\
\hline IFA (-) and ELISA (+) & positive & 1 & 4 & - \\
& positive & 1 & 8 & - \\
& positive & 1 & 4 & - \\
& positive & 1 & 4 & - \\
& positive & 1 & 2 & - \\
& positive & 1 & 2 & - \\
& positive & 1 & $<2$ & + \\
& positive & 1 & 8 & - \\
& positive & 1 & 2 & - \\
IFA (+) and ELISA (-) & positive & 1 & 2 & - \\
\hline
\end{tabular}

10. Dee, S. A. and Joo, H. S. 1994. Prevention of the spread of porcine reproductive and respiratory syndrome virus in endemically infected pig herds by nursery depopulation.Vet. Rec. 135: 6-9.

11. Denac, H., Moser, C., Tratschin, J. D. and Hofmann, M. A. 1997. An indirect ELISA for the detection of antibodies against porcine reproductive and respiratory syndrome virus using recombinant nucleocapsid protein as antigen. J. Virol. Methods 65: $169-181$.

12. Halbur, P. G., Paul, P. S., Frey, M. L., Lnadgraf, J., Eernisse, K., Meng, X. J., Andrews, J. J., Lum, M. A. and Rathje, J. A. 1996. Comparison of the antigen distribution of two US porcine reproductive and respiratory syndrome virus isolates with that of the Lelystad virus. Vet. Pathol. 33: 159-170.

13. Jusa, E. R., Inaba, Y., Kouno, M., Hirose, O., Shibata, I., Kubota, M. and Yasuhara, H. 1996. Slow-reacting and complement-requiring neutralizing antibody in swine infected with porcine reproductive and respiratory syndrome (PRRS) virus. J. Vet. Med. Sci. 58: 749-753.

14. Kono, Y., Kanno, T., Shimizu, M., Yamada, S., Ohashi, S., Nakamine, M. and Shirai, J. 1996. Nested PCR for detection and typing of porcine reproductive and respiratory syndrome (PRRS) virus in pigs. J. Vet. Med. Sci. 58: 941-946.

15. Murakami, Y., Kato, A., Tsuda, T., Morozumi, T., Miura, Y. and Sugimura, T. 1994. Isolation and serological characterization of porcine reproductive and respiratory syndrome (PRRS) viruses from pigs with reproductive and respiratory disorders in Japan. J. Vet. Med. Sci. 56: 891-894.

16. Nelson, E. A., Christopher-Hennings, J., Drew, T., Wensvoort, G., Collins, J. E. and Benfield, D. A. 1993. Differentiation of U. S. and European isolates of porcine reproductive and respiratory syndrome virus by monoclonal antibodies. J. Clin. Microbiol. 31: 3184-3189.

17. Nodelijk, G., Leengoed, L. A. M. G. V., Schoevers, E. J., Kroese, A. H., Jong, M. C. M. D., Wensvoort, G. and Verheijden, J. H. V. 1997. Seroprevalence of porcine reproductive and respiratory syndrome virus in Dutch weaning pigs. Vet. Microbiol. 56: 21-32.

18. Ogawa, T. and Hatakeyama, H. 1997. Economic assessment of disease losses on farms affected for the first time with the porcine reproductive and respiratory syndrome. Bull. Natl. Inst. Anim. Health 104: 1-8.

19. Pejsak, Z., Stadejek, T. and Markowska-Daniel, I. 1997. Clinical signs and economic losses caused by porcine reproductive and respiratory syndrome virus in a large breeding farm. Vet. 
Microbiol. 55: 317-322.

20. Shimizu, M., Yamada, S., Murakami, Y., Morozumi, T., Kobayashi, H., Mitani, K., Ito, N., Kubo, M., Kimura, K., Kobayashi, M., Yamamoto, K., Miura, Y., Yamamoto, T. and Watanabe, K. 1994. Isolation of porcine reproductive and respiratory syndrome (PRRS) virus from Heko-Heko disease of pigs. J. Vet. Med. Sci. 56: 389-391.

21. Solano, G. I., Segales, J., Colins, J. E., Molitor, T. W. and Pijoan, C. 1997. Porcine reproductive and respiratory syndrome virus (PRRSV) interaction with Haemophilus parasuis. Vet. Microbiol. 55: 247-257.

22. Takikawa, N., Kobayashi, S., Ide, S., Yamane, Y., Tanaka, Y. and Yamagishi, H. 1996. Detection of antibodies against porcine reproductive and respiratory syndrome (PRRS) virus in swine sera by enzyme-linked immunosorbent assay. J. Vet. Med. Sci. 58: 355-357.

23. Takikawa, N., Kobayashi, S., Ide, S., Yamane, Y., Tanaka, Y., Higashihara, M. and Yamagishi, H. 1997. Early serodiagnosis of porcine reproductive and respiratory syndrome virus infection of pigs by detection of slow-reacting and complementrequiring neutralizing antibody. J. Vet. Med. Sci. 59: 31-34.

24. Wensvoort, G., Terpstra, C., Pol, J. M. A., ter Laak, E. A., Bloemraad, M., de Kluyver, E. P., Kragten, C., van Buiten, L., den Besten, A., Wagenaar, F., Broekhuijsen, J. M., Moonen, P. L. J. M., Zetstra, T., de Boer, E. A., Tibben, H. J., de Jong, M. F., van't Veld, P., Groenland, G. J. R., van Gennep, J. A., Voets, M. T., Verheijden, J. H. M. and Braamskamp, J. 1991. Mystery disease in the Netherlands: the isolation of Lelystad virus. Vet. Quart. 13: 121-130.

25. Yahara, Y. 1994. PRRS virus isolation and serological survey in Japan. Proc. Jpn. Pig Vet. Soc. 24: 10-13.

26. Yoon, I. J., Joo, H. S., Christianson, W. T., Kim, H. S., Collins, J. E., Carlson, J. H. and Dee, S. A. 1992. Isolation of a cytopathic virus from weak pigs on farms with a history of swine infertility and respiratory syndrome. J. Vet .Diagn. Invest. 4: 139-143.

27. Yoon, I. J., Joo, H. S., Christianson, W. T., Kim, H. S., Collins, J. E., Morrison, R. B. and Dial, G. D. 1992. An indirect fluorescent antibody test for the detection of antibody to swine infertility and respiratory syndrome virus in swine sera. J. Vet. Diagn. Invest. 4: 144-147.

28. Yoon, I. J., Joo, H. S., Christianson, W. T., Morrison, R. B. and Dial, G. D. 1993. Persistent and contact infection in nursery pigs experimentally infected with porcine reproductive and respiratory syndrome (PRRS) virus. Swine Health Prod. 1: 5-8.

29. Yoon, I. J., Joo, H. S., Goyal, S. M. and Molitor, T. W.1994. A modified serum neutralization test for the detection of antibody to porcine reproductive and respiratory syndrome virus in swine sera. J. Vet. Diagn. Invest. 6: 289-292.

30. Yoon, K. J., Zimmerman, J. J., Swenson, S. L., McGinley, M. J., Eernisse, K. A., Brevik, A., Rhinehart, L. L., Frey, M. L., Hill, H. T. and Platt, K. B. 1995. Characterization of the humoral immune response to porcine reproductive and respiratory syndrome (PRRS) virus infection. J. Vet. Diagn. Invest. 7: 305-312. 